\title{
Utility of Single-Photon Emission Computed Tomography/Computed Tomography Fusion Imaging With 99mTc-Pyrophosphate Scintigraphy in the Assessment of Cardiac Transthyretin Amyloidosis
}

Noriko Tsuda, MD; Shinya Shiraishi, MD, PhD; Seitaro Oda, MD, PhD; Koji Ogasawara, MD;

Fumi Sakamoto, MD, PhD; Seiji Tomiguchi, MD, PhD; Koichiro Fujisue, MD, PhD;

Seiji Takashio, MD, PhD; Yasuhiro Izumiya, MD, PhD; Kenichi Tsujita, MD, PhD;

Yukio Ando, MD, PhD; Yasuyuki Yamashita, MD, PhD

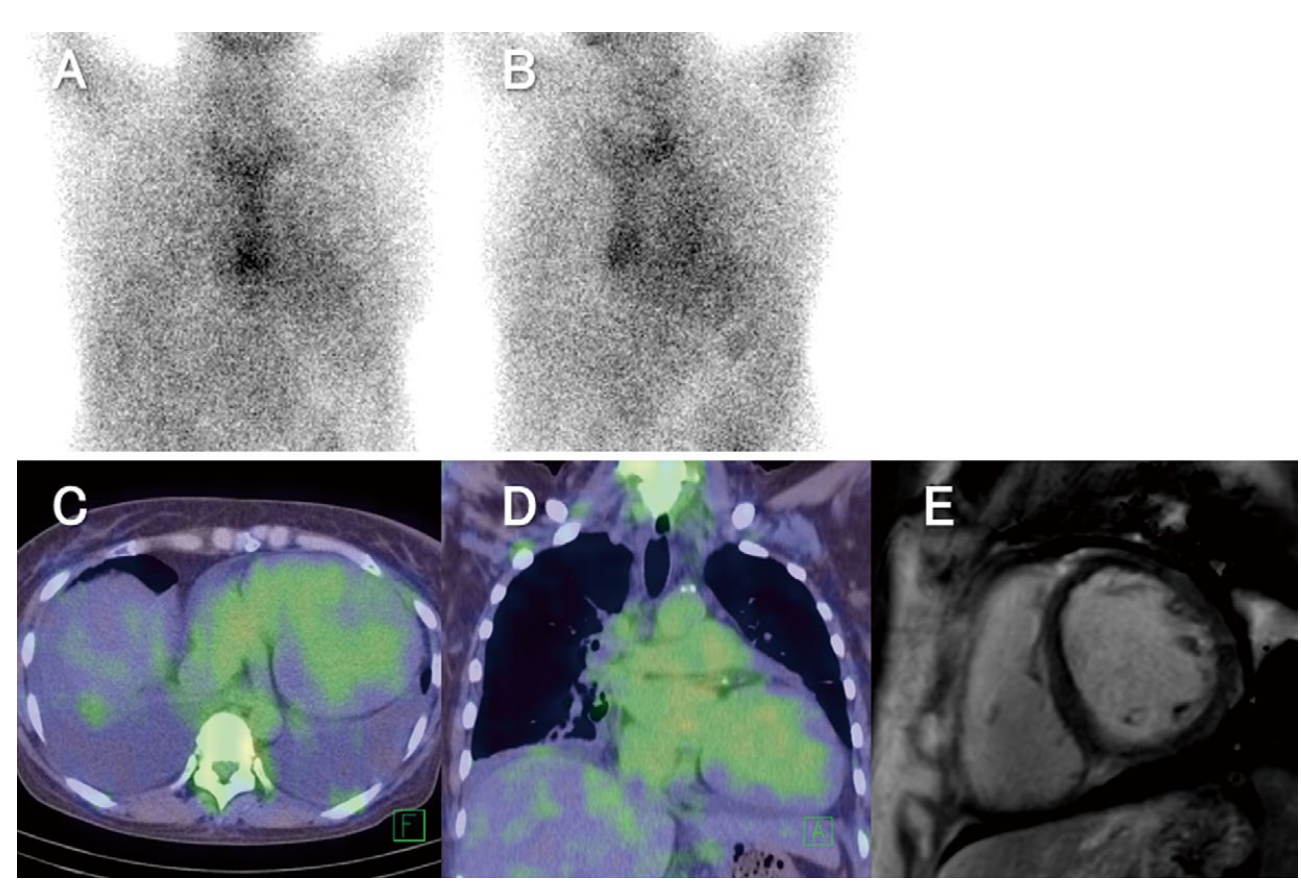

Figure. (A,B) Technetium-99m-pyrophosphate (99mTc-PYP) scintigraphy showed moderate cardiac uptake on planar imaging (A, frontal view; B, oblique view). (C,D) Single-photon emission computed tomography/computed tomography fusion imaging clearly visualized the cardiac uptake to be in the cardiac blood pool and not in the myocardium (C, axial image; $\mathbf{D}$, coronal image). (E) Cardiac magnetic resonance imaging showed no myocardial late gadolinium enhancement.

$\mathrm{C}$ ardiac transthyretin amyloidosis (ATTR) is increasingly recognized as an important cause of heart failure with preserved ejection fraction, and a growing public health problem with an increasing prevalence. ${ }^{1}$ Cardiac uptake on bone scintigraphy with techne- tium-99 m-pyrophosphate ( $99 \mathrm{~m}$ Tc-PYP) has been shown to have high diagnostic performance in the differentiation of cardiac ATTR from non-ATTR heart failure. ${ }^{2,3}$

A 52-year-old woman with heart failure was admitted to hospital. On ${ }^{99} \mathrm{~m}$ Tc-PYP scintigraphy to assess for cardiac

Received October 13, 2017; accepted November 6, 2017; released online December 2, 2017 Time for primary review: 24 days Department of Diagnostic Radiology (N.T., S.S., S.O., K.O., F.S., S. Tomiguchi, Y.Y.), Department of Cardiology (K.F.,

S. Takashio, Y.I., K.T.), Department of Neurology (Y.A.), Faculty of Life Sciences, Kumamoto University, Kumamoto, Japan

Mailing address: Seitaro Oda, MD, PhD, Department of Diagnostic Radiology, Faculty of Life Sciences, Kumamoto University,

1-1-1 Honjyo, Chuo-ku, Kumamoto 860-8556, Japan. E-mail: seisei0430@nifty.com

ISSN-1346-9843 All rights are reserved to the Japanese Circulation Society. For permissions, please e-mail: cj@j-circ.or.jp 
amyloidosis, moderate cardiac uptake on planar imaging was seen (Figure A,B). Single-photon emission computed tomography/computed tomography (SPECT/CT) fusion imaging, however, clearly visualized the cardiac uptake in the cardiac blood pool, and not in the myocardium (Figure C,D). Subsequent cardiac magnetic resonance imaging showed no myocardial late gadolinium enhancement (Figure E). On endomyocardial biopsy, myocardial interstitial fibrosis and negative amyloid deposition were confirmed. The patient was finally diagnosed with dilated cardiomyopathy.

In a recent multicenter study, bone scintigraphy had $>99 \%$ sensitivity and $86 \%$ specificity for detecting cardiac ATTR. ${ }^{2}$ Although ${ }^{99 \mathrm{~m} T c-P Y P}$ physiologically stays in the cardiac blood pool and can cause false-positive scintigrams, the present report is the first to show that SPECT/CT fusion imaging can provide better and more useful anatomical information to distinguish myocardial $99 \mathrm{~m}$ Tc-PYP uptake from tracer accumulation in the cardiac blood pool in the assessment of cardiac ATTR.

\section{Disclosures}

The authors declare no conflict of interest.

\section{References}

1. Gonzalez-Lopez E, Gallego-Delgado M, Guzzo-Merello G, de Haro-Del Moral FJ, Cobo-Marcos M, Robles C, et al. Wild-type transthyretin amyloidosis as a cause of heart failure with preserved ejection fraction. Eur Heart J 2015; 36: 2585-2594.

2. Gillmore JD, Maurer MS, Falk RH, Merlini G, Damy T, Dispenzieri A, et al. Nonbiopsy diagnosis of cardiac transthyretin amyloidosis. Circulation 2016; 133: 2404-2412.

3. Castano A, Haq M, Narotsky DL, Goldsmith J, Weinberg RL, Morgenstern R, et al. Multicenter study of planar technetium $99 \mathrm{~m}$ pyrophosphate cardiac imaging: Predicting survival for patients with ATTR cardiac amyloidosis. JAMA Cardiol 2016; 1: $880-889$. 